\title{
Follicular growth pattern in cyclic rats from late pro-oestrus to early oestrus
}

\author{
F. Gaytán ${ }^{1}$, C. Bellido ${ }^{2}$, C. Morales ${ }^{3}$, E. Aguilar $^{2}$ and \\ J. E. Sánchez-Criado ${ }^{2}$ \\ Depts of ${ }^{1}$ Cell Biology, ${ }^{2}$ Physiology and ${ }^{3}$ Pathology, Faculty of Medicine, University of Cordoba, Spain
}

\begin{abstract}
Adult cyclic rats were studied from $16: 00 \mathrm{~h}$ on pro-oestrus to $07: 00 \mathrm{~h}$ on oestrus to relate the cyclic hormonal changes to the proliferative activity and growth pattern of growing follicles. The proliferative activity was studied by 5-bromodeoxyuridine (BrdU) labelling and by the presence of mitoses. Small growing follicles (less than $275 \mu \mathrm{m}$ in diameter) were divided into five classes: multilaminar classes a (Ma, up to $75 \mu \mathrm{m}$ in diameter), $\mathrm{b}(\mathrm{Mb}$, 76-150 $\mu \mathrm{m}), c(\mathrm{Mc}, 15 \mathrm{I}-200 \mu \mathrm{m})$ and $\mathrm{d}(\mathrm{Md}, 201-274 \mu \mathrm{m})$ and follicles measuring $\geq 275 \mu \mathrm{m}$ in diameter were considered as $\geq$ class 1 , following previous classifications. LH concentrations were maximal at $18: 30 \mathrm{~h}$ on pro-oestrus, and this was coincident with an increase in $\mathrm{FSH}$, prolactin and progesterone concentrations, whereas oestradiol and testosterone concentrations were decreased. From 02:00 h on oestrus the concentrations of all hormones, except those of FSH, were decreased. The number of $\mathrm{Ma}, \mathrm{Mb}$ and $\mathrm{Mc}$ follicles did not change during pro-oestrus-oestrus, whereas an increase in the number of follicles $\geq$ class 1 was found at $07: 00 \mathrm{~h}$ on oestrus. This appears to be a consequence of the increased proliferative activity of $\mathrm{Md}$ follicles, evidenced by the increase in the BrdU labelling and mitotic index of this follicle class, found from 02:00 to 07:00 h on oestrus, together with a decrease in the percentage of early atretic follicles $\geq$ class 1 at 07:00 $\mathrm{h}$ on oestrus. This study provides an improved classification of small growing follicles into discrete classes and delineates a size class of follicles (Md follicles) that is responsive to the cyclic hormonal changes on early oestrus.
\end{abstract}

\section{Introduction}

The oestrous cycle is regulated by the coordinated actions of pituitary and ovarian hormones. The most marked changes in hormone concentrations during the cycle occur from late pro-oestrus to early oestrus. These include the preovulatory luteinizing hormone (LH), follicle-stimulating hormone (FSH) and prolactin surges, a preovulatory increase in the concentration of progesterone and decreases in those of testosterone and oestradiol (Gay et al., 1970; Barraclough et al., 1971; Butcher et al., 1974; Smith et al., 1975). In connection with these changes in hormone concentrations, crucial events occur in the ovary at both cell and tissue levels, such as the resumption of the meiotic process in the oocytes from preovulatory follicles, the initial luteinization of these follicles and their rupture to become post-ovulatory follicles, and the selection of the growing follicles destined to ovulate in the next cycle (Hirshfield and Midgley, 1978a; Butcher and Kirkpatrick-Keller, 1984).

Although the relationships between hormonal changes and ovarian events are well established in broad outline, several aspects are not fully understood. The growth of the ovarian follicles is a continuous process from the primordial resting to

Received 16 September 1996 the Graafian preovulatory follicles. It is generally agreed that large follicles are under the control of gonadotrophic hormones. However, the factors regulating the growth of small follicles are not well understood. Although it has been well documented that small follicles are influenced by pituitary hormones (reviewed by Greenwald and Terranova, 1988), there is still some controversy about whether growth of small follicles occurs in hypophysectomized animals (Greenwald and Terranova, 1988). Quantitative studies along the cycle have shown that large follicles (from about $260 \mu \mathrm{m}$ in diameter onward) are recruited in pro-oestrus-oestrus (Hirshfield and Midgley, 1978a; Butcher and Kirkpatrick-Keller, 1984; van Cappellen et al., 1993). However, the recruitment of these follicles may be due to increased growth of smaller follicles or to prevention of atresia.

Gaytán ef al. (1996) proposed a classification of small follicles based on follicle size and proliferative activity, and reported that the use of the 5-bromodeoxyuridine ( $\mathrm{BrdU})$ technique is an adequate method for assessing follicle growth and early atresia, as well as for identifying labelled cell types based on their morphological features. The objective of this study was to relate the hormonal changes that happen from late pro-oestrus to early oestrus to the selection of the cohort of follicles that will grow into large follicles during the next cycle. For this, we determined the peripheral serum hormone concentrations, the 
growth pattern and the proliferative activity of small follicles, in cyclic rats, from 16:00 h on pro-oestrus to $07: 00 \mathrm{~h}$ on oestrus.

\section{Materials and Methods}

\section{Animals and treatments}

Adult female Wistar rats (body mass $205 \pm 10 \mathrm{~g}$ ) were maintained under controlled light ( $14 \mathrm{~h}$ light:10 h dark, lights on at 05:00 h) and temperature $\left(20-22^{\circ} \mathrm{C}\right)$ and had free access to rat chow and tap water. Vaginal smears were examined daily. Only rats showing at least two consecutive 4 day cycles were used. 5-Bromodeoxyuridine (BrdU, Sigma, St Louis, MO) and a monoclonal antibody against BrdU (Dako Diagnostica, Hamburg) were used.

Groups of ten rats were killed at 16:00,18:30 and 21:00 h in pro-oestrus, and at 02:00 and 07:00 h in oestrus. One hour before death, the animals were injected i.p. with $50 \mathrm{mg} \mathrm{BrdU}$ $\mathrm{kg}^{-1}$ in $\mathrm{I}$ mol Tris-HCl l-1-buffered saline, $\mathrm{pH}$ 7.6. Five rats at each time point (except for those killed at $18: 30 \mathrm{~h}$ in pro-oestrus) were used for the morphometric and immunohistochemical study.

\section{Tissue processing}

Both ovaries were carefully dissected and fixed for $24 \mathrm{~h}$ in Bouin-Hollande's fluid $\left(0.20 \mathrm{~mol}\right.$ picric acid $1^{-1}, 0.12 \mathrm{~mol}$ copper acetate $l^{-1}$ and $4 \%(\mathrm{v} / \mathrm{v})$ formaldehyde in water). After dehydration, the ovaries were embedded in paraffin wax. For the immunohistochemical detection of DNA-incorporated $\mathrm{BrdU}$, the left ovaries of five rats at each time point were serially sectioned ( $4 \mu \mathrm{m}$ in thickness) and placed on poly-Llysine-coated slides. The right ovaries of four rats at each time point were serially sectioned ( $5 \mu \mathrm{m}$ in thickness), stained with alcian blue-haematoxylin and eosin and used for counting the total number of follicles. Alcian blue staining allows a clear distinction of the basement membrane.

\section{Immunohistochemical localization of BrdU}

Immunohistochemistry was carried out as described by Gaytán et al. (1996). Briefly, slides were dried at $37^{\circ} \mathrm{C}$ for $18 \mathrm{~h}$ and after dewaxing, endogenous peroxidase was inhibited by incubation for $30 \mathrm{~min}$ in $0.2 \%(\mathrm{w} / \mathrm{v})$ hydrogen peroxide in methanol. After rehydration in graded ethanol, the sections

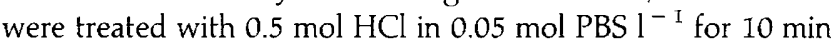
at $4^{\circ} \mathrm{C}$ and with $2 \mathrm{~mol} \mathrm{HCl}$ in $0.05 \mathrm{~mol} P B S 1^{-1}$ for $10 \mathrm{~min}$ at room temperature. The sections were then rinsed in $0.1 \mathrm{~mol}$ borate buffer $\mathrm{I}^{-1}$ with $10 \%(\mathrm{v} / \mathrm{v})$ Triton $\mathrm{X}(\mathrm{pH} 8.5)$ for $10 \mathrm{~min}$. After rinsing in PBS, the sections were blocked with $10 \%(\mathrm{v} / \mathrm{v})$ normal rabbit serum for $2 \mathrm{~h}$ and incubated overnight with a mouse monoclonal antibody against BrdU diluted 1:200. Afterwards, the sections were processed according to the avidinbiotin complex (ABC) method (Hsu et al., 1981). Sections were treated sequentially with rabbit anti-mouse IgG-biotin conjugate (Sigma, London 1:1000 $\mathrm{th}$ at room temperature), and avidin-biotin peroxidase complex (Vector Labs, Burlingame, $\mathrm{CA}, \mathrm{I} \mathrm{h}$ at room temperature). Tissue-bound peroxidase was visualized by incubation in $0.03 \%(\mathrm{w} / \mathrm{v})$ diaminobenzidinetetrahydrochloride (Type IV, Sigma) $0.01 \%(\mathrm{v} / \mathrm{v})$ hydrogen peroxide in $0.1 \mathrm{~mol}$ Tris $\mathrm{I}^{-1}$ buffer $(\mathrm{pH} \mathrm{7.6)}$ ) for $1 \mathrm{~min}$. Afterwards, sections were darkened in $1 \%(\mathrm{w} / \mathrm{v})$ copper sulphate for $5 \mathrm{~min}$ and counterstained with haematoxylin.

\section{Follicle counting}

Follicles were classified into two groups: small follicles, measuring less than $275 \mu \mathrm{m}$ in diameter in the largest crosssection (LCS) and large follicles, measuring $275 \mu \mathrm{m}$ in diameter or more. Small growing follicles were classified as reported by Gaytán et al. (1996) with slight modifications. Multilaminar class a follicles showed more than one layer of granulosa cells and were up to $75 \mu \mathrm{m}$ in diameter, multilaminar class b follicles measured from 76 to $150 \mu \mathrm{m}$, multilaminar class $\mathrm{c}$ from 151 to $200 \mu \mathrm{m}$ and multilaminar class $\mathrm{d}$ from 201 to $274 \mu \mathrm{m}$. Large follicles were divided into classes $1-5$ as described by Osman (1985) and Gaytán et al. (1996). Preovulatory class 5 follicles that were present from 16:00 h on pro-oestrus to $02: 00 \mathrm{~h}$ on oestrus and postovulatory follicles found at $07: 00 \mathrm{~h}$ on oestrus were not considered in this study. The total number of healthy multilaminar a, b, c, d and large follicles (no follicles larger than class 3 were found) per ovary were counted in four rats at each time point. Two diameters at right angles were measured in the cross-section containing the oocyte nucleolus. The mean diameter of each follicle class was also recorded. Atretic type Ia follicles (those showing alterations exclusively in isolated areas of the granulosa cell layer; Osman, 1985) were also counted. Follicles with more advanced atresia were not counted because they represent old atretic follicles and, furthermore, the follicle size at which atresia started had been modified.

From the results obtained in the morphometric study of the follicles, we decided to analyse the labelling and mitotic indices of multilaminar classes $\mathrm{c}$ and $\mathrm{d}$ follicles. For this, unstained serial sections from the left ovaries of five rats per group were observed under phase-contrast microscopy and those containing the largest cross-sections of $\mathrm{Mc}$ or $\mathrm{Md}$ follicles were immunostained and the number of BrdU-labelled granulosa cells counted. As counting the total number of granulosa cells in follicles larger than $\mathrm{Mb}$ follicles was impractical, the labelling index was expressed as the number of BrdU-labelled cells per unit area of the granulosa cell layer. The area of the granulosa was measured with an image analyser. The mitotic index was obtained by counting the number of mitotic figures in granulosa cells (Fig. 3b) in the same follicles and expressed per unit area. From 15 to 20 follicles in each follicle class per rat in five rats at each time point were scored.

\section{Radioimmunoassays}

Serum concentrations of $\mathrm{LH}, \mathrm{FSH}$ and prolactin were measured in duplicate in $25 \mu \mathrm{l}$ samples using double-antibody radioimmunoassay kits supplied by the NIH (Bethesda, MD) according to methods described by Sánchez-Criado et al. (1990). Rat LH-I-9, FSH-I-8 and PRL-I-6 were labelled with ${ }^{125}$ I 

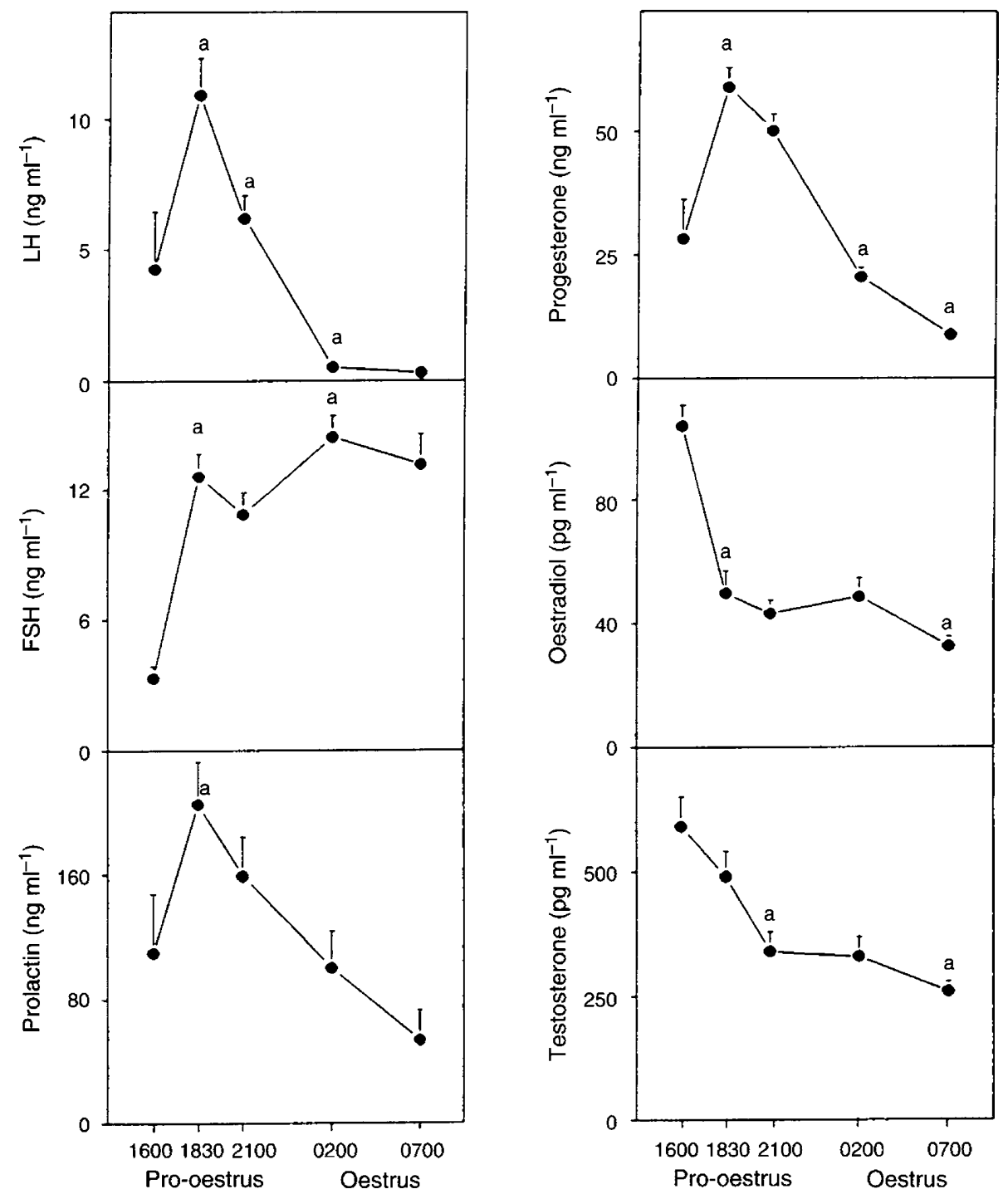

Fig. 1. Serum hormone concentrations from late pro-oestrus to early oestrus. (a) $P<0.01$ versus the values of the previous time point. The data are the means \pm SEM for $n=8-10$. ANOVA and Tukey's test.

by the chloramine T method (Greenwood et al., 1963). LH, FSH and prolactin concentrations were expressed as $\mathrm{ng} \mathrm{ml}^{-1}$ serum of the reference preparations LH-rat-RP-3, FSH-rat-RP-2 and PRL-rat-RP-3. All samples were analysed in the same assay and the intra-assay coefficients of variation were $8 \%, 7 \%$ and $9 \%$ for LH, FSH and prolactin, respectively. The sensitivity of the assays were $7.5,20$ and $10 \mathrm{pg}$ per tube for LH, FSH and prolactin, respectively.

Serum concentrations of progesterone, oestradiol and testosterone were determined using commercial kits (Diagnostic Products Corporation, Los Angeles, CA). Values are expressed as $\mathrm{ng} \mathrm{ml}^{-1}$ for progesterone and $\mathrm{pg} \mathrm{ml}^{-1}$ for oestradiol and testosterone. All samples were analysed in the same assay, and the intra-assay coefficients of variation were $4 \%, 6 \%$ and $5 \%$ for progesterone, oestradiol and testosterone, respectively.

Statistical analysis was performed by ANOVA and Tukey's test. Significance was considered when $P \leq 0.05$.

\section{Results}

The maximum preovulatory LH concentration was found at $18: 30 \mathrm{~h}$ in pro-oestrus, and was coincident with an increase in the serum concentrations of FSH, prolactin and progesterone, whereas the concentrations of oestradiol and testosterone decreased through late pro-oestrus and early oestrus (Fig. 1). The concentrations of all hormones were decreased from $02: 00 \mathrm{~h}$ on oestrus onwards, except those of FSH which remained high.

Several cohorts of growing follicles were found at all time points. Although the lower limit of $\mathrm{Ma}$ follicles was determined by the presence of more than one single layer of granulosa cells (GC), the smallest Ma follicles measured more than $45 \mu \mathrm{m}$ in diameter (Fig. 2). Antrum was already present in some large $\mathrm{Mb}$ follicles. BrdU-labelled cells and mitotic figures were observed in all follicle types at the different time points, but BrdU-labelled GC were particularly abundant in Md follicles at 

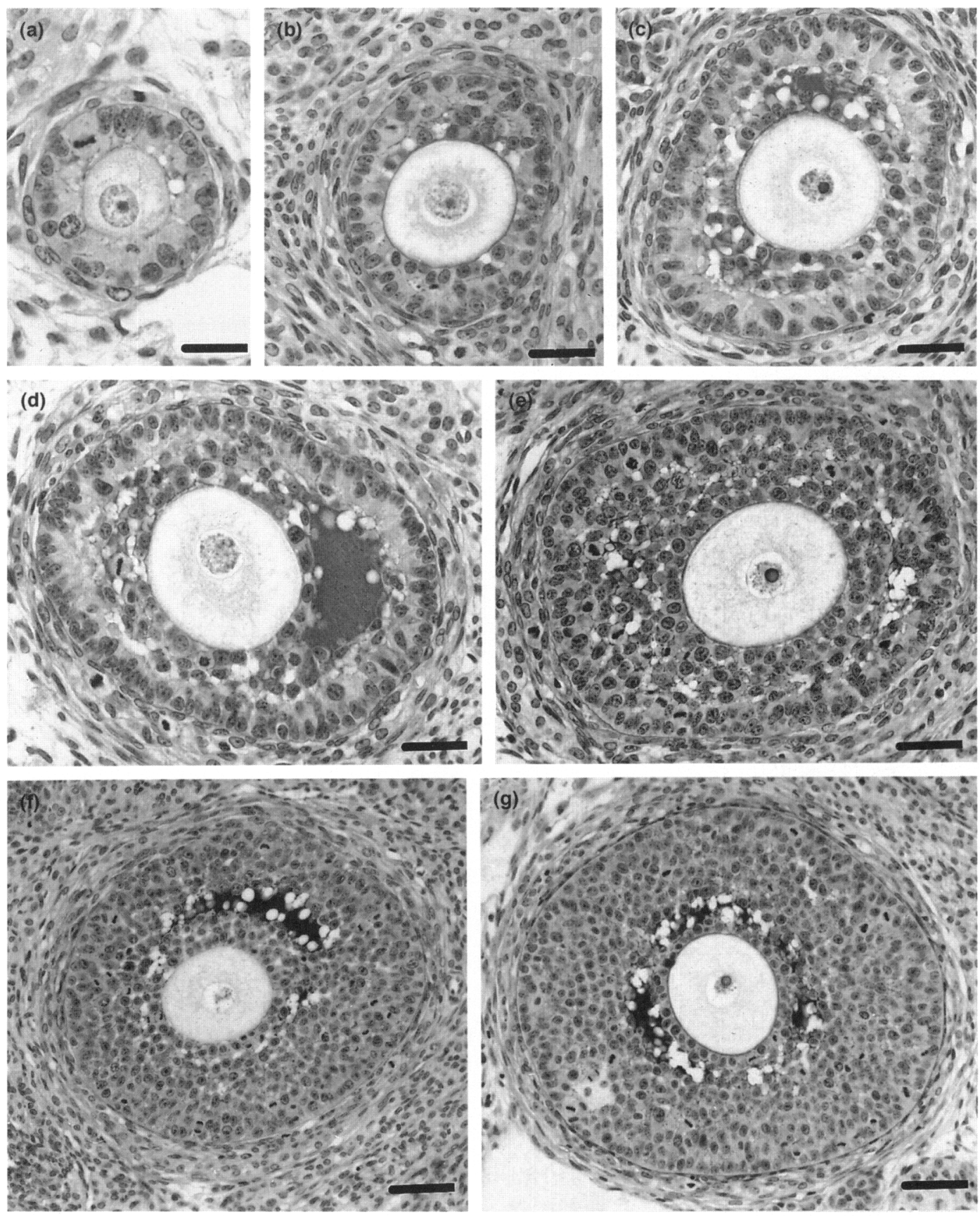

Fig. 2. Micrographs of the different classes of follicle. (a) Multilaminar class a (Ma; $62 \mu \mathrm{m}$ in diameter) follicle, (b-c) multilaminar class b (Mb; 100 and $148 \mu \mathrm{m}$ in diameter, respectively) follicles, (d) multilaminar class c (Mc; $170 \mu \mathrm{m}$ in diameter) follicle, (e-f) multilaminar class $\mathrm{d}(\mathrm{Md} ; 210$ and $265 \mu \mathrm{m}$ in diameter, respectively) follicles and (g) class I $(320 \mu \mathrm{m}$ in diameter) follicle. Alcian blue, haematoxylin and eosin. Scale bars correspond to $22 \mu \mathrm{m}$ in (a), $32 \mu \mathrm{m}$ in (b-d), $38 \mu \mathrm{m}$ in (e) and $53 \mu \mathrm{m}$ in ( $f-g)$.

02:00 and 07:00 h on oestrus (Fig. 3a) and mitotic figures in Md follicles at 07:00 h (Fig. 3b).

No significant changes in the number of healthy follicles per ovary were found for $\mathrm{Ma}, \mathrm{Mb}$ or $\mathrm{Mc}$ follicles, whereas the number of $\mathrm{Md}$ follicles was slightly increased at $07: 00 \mathrm{~h}$ on oestrus (Fig. 4). Follicles of class 1 or larger follicles were absent in some rats or present in very small numbers ( $1-3$ follicles per ovary) at $16: 00 \mathrm{~h}$ on pro-oestrus, were present in small numbers (10-12 follicles per ovary) at 21:00 h on pro-oestrus and 02:00 $\mathrm{h}$ on oestrus, and there were considerably more (36 follicles per ovary) at 07:00 $\mathrm{h}$ on oestrus. The mean follicle diameters of classes $\mathrm{Ma}$ to $\mathrm{Mc}$ follicles did not change, but an increase in the mean diameter of Md follicles (from 231.3 \pm 3.1 to $242.8 \pm 1.3 \mu \mathrm{m}$, mean \pm SEM for $n=4$ ) and of follicles $\geq$ class 1 (from $300.8 \pm 4.1$ to $371.3 \pm 6.3 \mu \mathrm{m}$, mean \pm SEM for $n=4$ ) was found from 02:00 to 07:00 h on oestrus. 

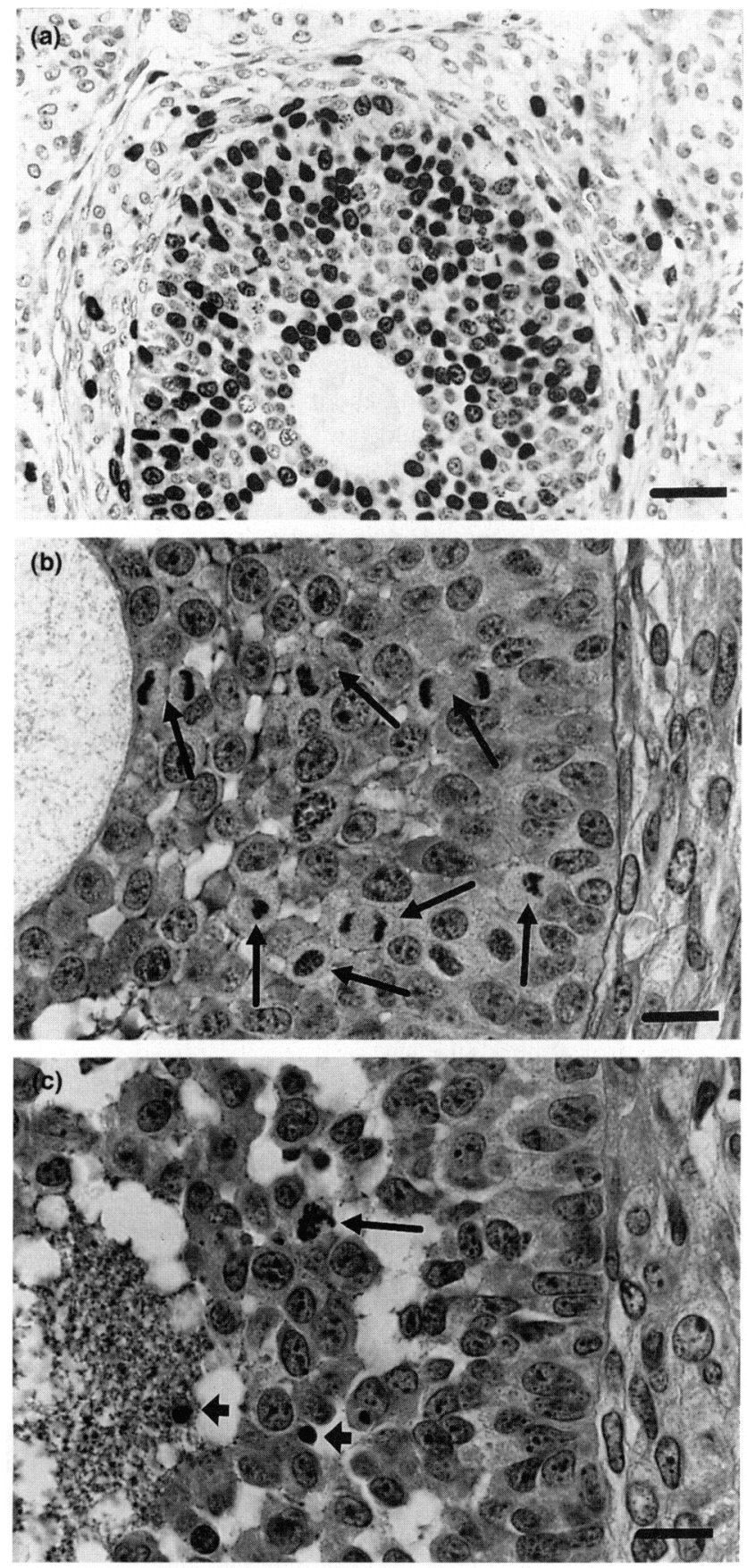

Fig. 3. Micrographs of Md follicles at $07: 00 \mathrm{~h}$ in oestrus. Large numbers of 5-bromodeoxyuridine ( $\mathrm{BrdU}$ )-labelled cells in immunostained sections (a) and mitotic figures (arrows) (b) can be observed. In early atretic follicles (c) the coexistence of mitosis (large arrow) and apoptotic bodies (short arrows) can be observed. (b) and (c) alcian blue, haematoxylin and eosin staining. Scale bars correspond to $35 \mu \mathrm{m}$ in (a) and to $14 \mu \mathrm{m}$ in $(b-c)$.

The labelling and mitotic indices of $\mathrm{Mc}$ follicles did not change significantly, whereas the labelling index of Md follicles was significantly increased (twofold) at 02:00 and 07:00 h on oestrus, and the mitotic index was also significantly increased (twofold) at 07:00 h on oestrus (Fig. 5).

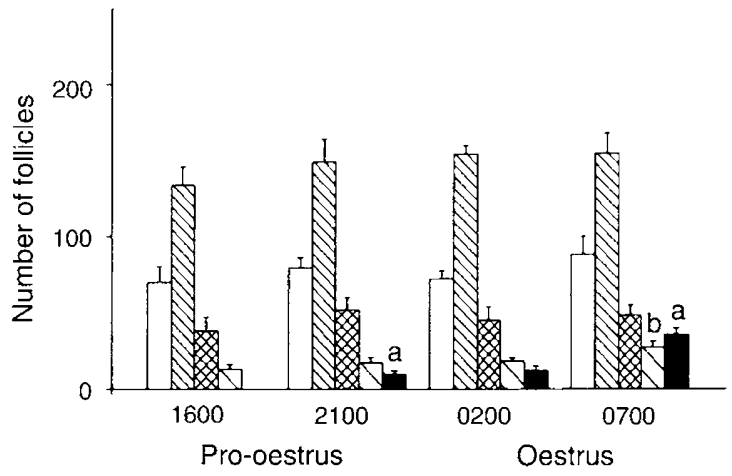

Fig. 4. Number of healthy multilaminar classes a (Ma, $\square), b(\mathrm{Mb}, \mathbb{Q})$, $c(\mathrm{Mc}, \mathrm{d}$ ), $(\mathrm{Md}, \nabla)$ follicles and of follicles $\geq$ class 1 ( $\geq 1 \mathbf{\square}$ ) from late pro-oestrus to early oestrus. (a) and (b) $P<0.01$ and $P<0.05$, respectively versus the values of the previous time point. The data are the means $\pm \operatorname{SEM}$ for $n=4$. ANOVA and Tukey's test.

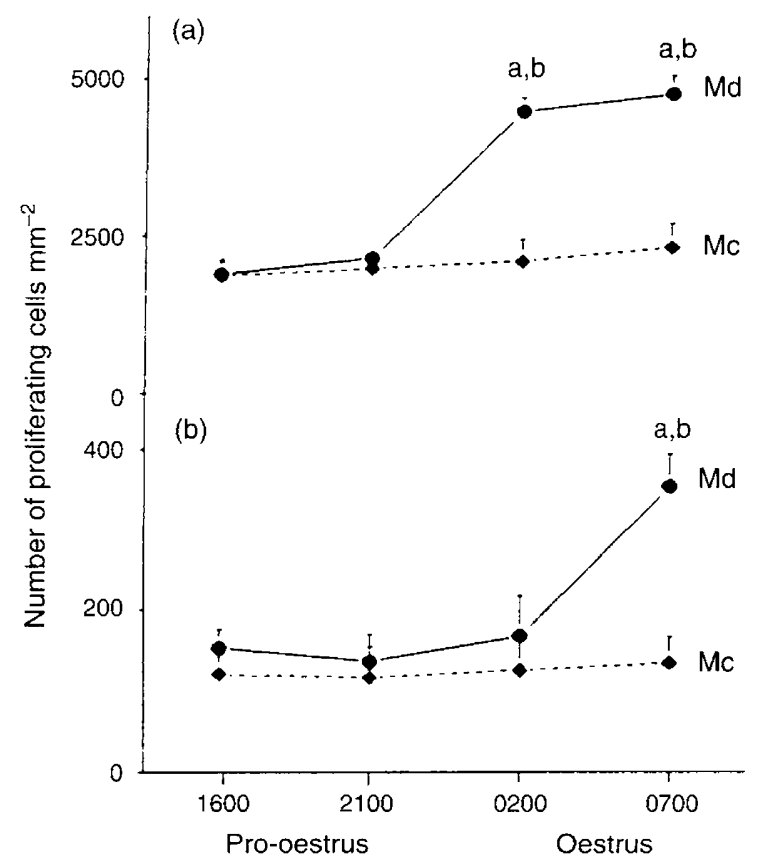

Fig. 5. Labelling and mitotic indices of multilaminar classes $\mathrm{c}$ and $\mathrm{d}$ ( $\mathrm{Mc}$ and $\mathrm{Md}$ ) follicles from late pro-oestrus to early oestrus. (a) $P<0.01$ versus the values of the previous time point (b) $P<0.01$ versus $\mathrm{Mc}$ follicles. The data are the means $\pm \operatorname{SEM}$ for $n=5$. ANOVA and Tukey's test.

Atretic type la follicles showed few picnotic granulosa cells, together with few mitotic figures (Fig. 3c). This type of atresia was observed only in Md follicles or in follicles $\geq$ class 1 . The percentage of atretic $\mathrm{Md}$ follicles represented a small percentage (about $5 \%$ ) and no differences among the different time points studied were found. Otherwise, about $50 \%$ of follicles $\geq$ class $I$ were atretic at $21: 00 \mathrm{~h}$ on pro-oestrus and at $02: 00 \mathrm{~h}$ on oestrus, but this percentage decreased to about $15 \%$ at $07: 00 \mathrm{~h}$ on oestrus (Fig. 6). Counts were not performed at $16: 00 \mathrm{~h}$ on pro-oestrus, since the total number of follicles $\geq$ class 1 was very small. 


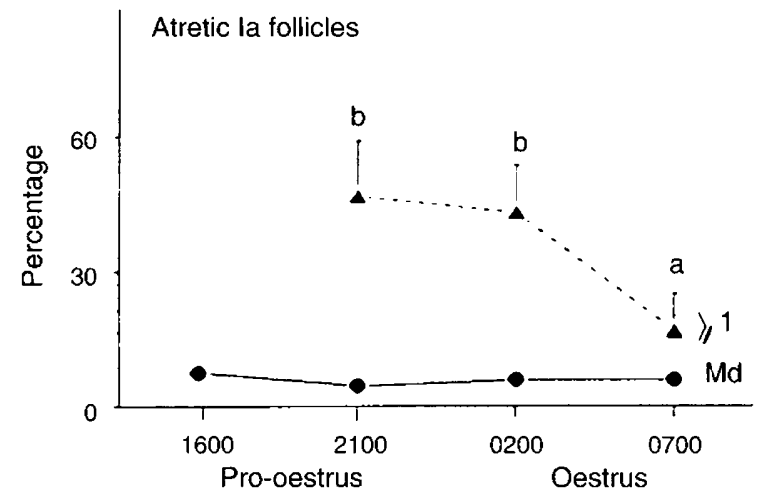

Fig. 6. Percentage of atretic type la multilaminar class $d(\mathrm{Md})$ follicles and of follicles $\geq$ class $1(\geq 1)$ with respect to the total number of follicles in each follicle class, from late pro-oestrus to early oestrus. (a) $P<0.01$ versus the values of the previous time point; (b) $P<0.01$ versus Md follicles. The data are the means $\pm \operatorname{seM}$ for $n=4$. ANOVA and Tukey's test.

\section{Discussion}

In a previous study (Gaytán et al., 1996), we proposed a classification of small follicles, based on size and proliferative activity. This has been slightly modified on the basis of the results provided by this study. Follicles measuring from 151 to $274 \mu \mathrm{m}$ in diameter, which were previously considered as a single class, are now divided into two classes (multilaminar classes $\mathrm{c}$ and d), because they had a different growth pattern on early oestrus. Whereas Mc follicles had a nearly constant proliferative activity on pro-oestrus-oestrus, Md follicles showed a marked increase in their proliferative activity on early oestrus. Follicle size seems to be the most reliable parameter for the study of the follicles that are responsive to cyclic hormone changes. The presence or absence of follicular antrum seems not to be a good marker of functional follicular development, since it is present in $\mathrm{Mb}, \mathrm{Mc}$ and Md follicles, which have a different growth pattern on pro-oestrus-oestrus.

Both the number of $\mathrm{Ma}, \mathrm{Mb}$ and $\mathrm{Mc}$ follicles and their mean follicle size were nearly constant from late pro-oestrus to early oestrus. This suggests that the growth rate of these follicle classes and, therefore, the renewal of follicles in each class were nearly constant during the period studied: i.e. the larger follicles in each class became the smaller of the following class. This could also explain the constancy of the mean follicle diameter in each follicle class, in spite of the growth of the follicles, evidenced by BrdU-labelling. Otherwise, a slight increase in the number of Md follicles (1.5-fold) and a more relevant increase in the number of follicles $\geq$ class $I$ (threefold) was found at 07:00 h on oestrus. These results are in agreement with previous morphometric (Hirshfield and Midgley, 1978a; Butcher and Kirkpatrick-Keller, 1984; van Cappellen et al., 1993) and autoradiographic (Groen-Kevlant, 1981) studies reporting that the number of small follicles did not show marked changes during the cycle and that follicles from 260 to $390 \mu \mathrm{m}$ in diameter (corresponding to large $\mathrm{Md}$ and classes I-2 in this study) are recruited between pro-oestrus and oestrus. Since follicles larger than $200 \mu \mathrm{m}$ in diameter represented a small proportion of the total number of follicles per ovary, the increase in the number of these follicles could be due to small changes in the relative numbers of $\mathrm{Ma}-\mathrm{Mc}$ follicles, which represented more than $80 \%$ of the total number of follicles.

In this study, the increase in the number of $\mathrm{Md}$ follicles and of follicles $\geq$ class 1 found at $07: 00 \mathrm{~h}$ on oestrus suggested an increased growth rate of the preceding follicle classes. Consequently, the labelling and mitotic indices of $\mathrm{Mc}$ and $\mathrm{Md}$ follicles were studied at the different time points. In accordance with the morphometric data, the labelling index of Md follicles was increased at 02:00-07:00 h on oestrus, and the mitotic index at 07:00 h on oestrus. Differences between these two proliferation markers (labelling and mitotic indices) was due to the interval between the $S$ and the $M$ phases of the cell cycle, detected repectively by BrdU-labelling and counting of mitotic cells. This sequence (an increase in the labelling index at both 02:00 and $07: 00 \mathrm{~h}$ and of the mitotic index exclusively at $07: 00 \mathrm{~h}$ ) indicates that the increase in the proliferative activity started by $02: 00 \mathrm{~h}$ and continued through $07: 00 \mathrm{~h}$ on oestrus. Multilaminar class d follicles (measuring 201-274 $\mu \mathrm{m}$ ) appear to represent a critical point in follicular development, since this cohort of follicles was responsive to the hormonal changes that occurred on pro-oestrus-oestrus. The slight increase in the number of Md follicles without a significant increase in the mean proliferative activity of $\mathrm{Mc}$ follicles was probably due to an increased growth of the largest Mc follicles that came into the Md follicle class, since the limit between both follicle classes is arbitrary.

Rescue from atresia has also been proposed as a mechanism responsible for the recruitment of follicles on oestrus (Schwartz, 1974; Hirshfield and Midgley, 1978b). In this study, the percentage of atretic la follicles was significantly decreased at 07:00 $\mathrm{h}$ in oestrus. Atretic follicles corresponded to Md follicles or to follicles $\geq$ class 1 , which is in accordance with previous studies indicating that most follicles (unless rescued) undergo atresia at $200-400 \mu \mathrm{m}$ in diameter (Hirshfield and Midgley, 1978a). Summarizing, follicle growth from late pro-oestrus to early oestrus appears to occur in two phases. First, follicles from classes Ma to Mc (i.e, from about 45 to $200 \mu \mathrm{m}$ in diameter) showed a basal, relatively constant growth rate that seems to be independent of cyclic hormone changes. Second, follicles of classes Md of larger (from $200 \mu \mathrm{m}$ onward) showed cyclic changes in their proliferative activity on early oestrus, probably in response to cyclic hormonal changes. A similar growth pattern has been proposed for human ovarian follicles (Gougeon, 1996). Furthermore, the selection of the follicles for the next cycle occurred by two different mechanisms: an increase in the proliferative activity of Md follicles, which enter into the pool of rapidly growing follicles (classes 1-3; Osman, 1985; Gaytán et al., 1996), and a decrease in the proportion of follicles $\geq$ class $I$ undergoing atresia. In a previous study on the development of antral follicles in 5 day cyclic rats, van Cappellen et al. (1993) found a 3.4-fold increase in the number of healthy follicles $\geq$ class 1 and a 0.22 -fold decrease in the proportion of early atretic follicles from $17: 00 \mathrm{~h}$ on pro-oestrus to $10: 00 \mathrm{~h}$ on oestrus. This is equivalent to the 3.6 -fold increase in the number of follicles $\geq$ class 1 and the 0.35 -fold decrease in the proportion of early atretic follicles found in this study, from $21: 00 \mathrm{~h}$ on pro-oestrus to $07: 00 \mathrm{~h}$ on oestrus. This indicates that this period is crucial for follicle development in spite of differences in the duration of the oestrous cycle. 
Several studies have indicated that the growth of small follicles is also influenced by gonadotrophins (Greenwald and Terranova, 1988). This contention is not in disagreement with the data of this study. Otherwise, these data indicate that follicles smaller than $200 \mu \mathrm{m}$ are not affected by cyclic hormone changes in pro-oestrus-oestrus, although their basal growth is probably influenced by tonic gonadotrophin stimulation. Furthermore, effects of FSH secretion after $07: 00 \mathrm{~h}$ on oestrus cannot be discarded from the data of this study.

The secondary FSH secretion has been considered as the main factor for the recruitment of the follicles (Schwartz, 1974; Hirshfield and Midgley, 1978b; Richards and Midgley, 1976). In this sense, high FSH concentrations were coincident with the increased proliferative activity in Md follicles, as well as with the decrease in the percentage of atretic follicles $\geq$ class 1 , suggesting that this hormone is responsible for these actions. Additional studies on experimental models involving changes in specific hormone concentrations in pro-oestrus-oestrus would be of interest for the study of the role of the different hormones in the cell and tissue changes that happen in the ovary at this time.

The authors are very grateful to the National Hormone and Pituitary Program (Baltimore, MD) for the RIA kits, to J. Molina, P. Cano and E. Tarradas for their technical assistance. This work was subsidized by grant PB94-0449 from the CAICYT (Spain).

\section{References}

Barraclough CA, Collu R, Massa R and Martini L (1971) Temporal interrelationships between plasma $\mathrm{LH}$, ovarian secretion rates and peripheral plasma progestin concentrations in the rat: effects of nembutal and exogenous gonadotropins Endocrinology 88 1347-1447

Butcher RL and Kirkpatrick-Keller D (1984) Patterns of follicular growth during the four-day oestrus cycle of the rat Biology of Reproduction 31 280-286

Butcher RL, Collins WE and Fugo NW (1974) Plasma concentrations of LH, FSH, prolactin, progesterone, oestradiol $17-\beta$ throughout the 4-day oestrus cycle of the rat Endocrinology 94 1704-1708
Gay VL, Midgley ARJr and Niswender GD (1970) Patterns of gonadotrophin secretion associated with ovulation Federation Proceedings 29 1880-1887

Gaytán F, Morales C, Bellido C, Aguilar E and Sánchez-Criado JE (1996) Proliferative activity in the different ovarian compartments in cycling rats estimated by the 5-Bromodeoxyuridine technique Biology of Reproduction 54 1356-1365

Gougeon A (1996) Regulation of ovarian follicular development in primates: facts and hypotheses Endocrine Reviews 17 121-155

Greenwald GS and Terranova PS (1988) Follicular selection and its control. In The Physiology of Reproduction Vol. I pp 387-455 Eds E Knobil and JD Neill. Raven Press, New York

Greenwood PC, Hunter WM and Glover JS (1963) The preparation of ${ }^{131} \mathrm{I}-$ labelled human growth hormone of high specific radioactivity Biochemical Journal 89 114-123

Groen-Kevlant AC (1981) An autoradiographic study of follicle growth in the ovaries of cyclic rats Acta Endocrinologica 96 377-381

Hirschfield AN and Midgley AR, Jr (1978a) Morphometric analysis of follicular development in the rat Biology of Reproduction 19 597-605

Hirschfield AN and Midgley AR (1978b) The role of FSH in the selection of large ovarian follicles in the rat Biology of Reproduction 19 606-611

Hsu SM, Raine L and Fanger H (1981) Use of avidin-biotin-peroxidase complex $(A B C)$ in immunoperoxidase techniques. A comparison between $A B C$ and unlabelled PAP procedures Journal of Histochemistry and Cytochemistry 29 $577-579$

Osman P (1985) Rate and course of atresia during follicular development in the adult cyclic rat Journal of Reproduction and Fertility 73 261-270

Richards JS and Midgley AR, Jr (1976) Protein hormone action: a key to understanding ovarian follicular and luteal cell development Biology of Reproduction 14 82-94

Sánchez-Criado JE, Bellido C, Galiot F, López FJ and Gaytán F (1990) A possible dual mechanism of the anovulatory action of antiprogesterone RU486 in the rat Biology of Reproduction 42 877-886

Schwartz NB (1974) The role of FSH and LH and of their antibodies on follicle growth and on ovulation Biology of Reproduction 10 236-272

Smith MS, Freeman ME and Neill JD (1975) The control of progesterone secretion during the oestrus cycle and early pseudopregnancy in the rat: prolactin, gonadotropin and steroid levels associated with rescue of the corpus luteum of pseudopregnancy Endocrinology 96 219-226

Van Cappellen WA, Osman P and Meijs-Roelofs HMA (1993) Model of antral follicle dynamics during the 5-day cycle in rats based on measurement of antral follicle inflow Journal of Reproduction and Fertility 99 57-63 